\title{
Evaluation of pomegranate peel fortified pan bread on body weight loss
}

\author{
Sayed-Ahmed, E. F. \\ Special Food and Nutrition Department, Food Technology Research Institute, ARC, Giza, Egypt
}

Email address:

Elsayed_farahat2003@yahoo.com

\section{To cite this article:}

Sayed-Ahmed, E. F.. Evaluation of Pomegranate Peel Fortified Pan Bread on Body Weight Loss. International Journal of Nutrition and Food Sciences. Vol. 3, No. 5, 2014, pp. 411-420. doi: 10.11648/j.ijnfs.20140305.18

\begin{abstract}
Pomegranate (Punica granatum L.) peel is a nutritive, antioxidant rich by-product, easily available after production of pomegranate juice and ready to eat arils. The aim of present study was to utilize of pomegranate peel powder (PPP) as a good source of fiber ingredient and antioxidant bioactive compounds to produce value add bakery product based on pomegranate peel powder $2.5 \%, 5 \%$, and $7.5 \%$ and investigation of weight loss activity in rats fed on high fat diet (HFD). Chemical composition, total phenols, total flavonoids and anti-oxidative activity (DPPH) of PPP and pan breads were determined. Texture profile analysis (TPA), sensory evaluation and physical properties of pan breads were investigated. Pan bread fortified with $2.5 \%$ and $5 \%$ PPP had higher score in overall acceptability and physical properties when compared to control pan bread and other various concentration (7.5\%) of PPP. Thirty-six female albino adult rats with an average weight $(180 \pm 5 \mathrm{~g})$ were divided into six groups 6 rats for each. The first group (G1) fed on basal diet as a (negative control group). The other rats (30 rat) were divided as follow : (G2) fed on HFD as a positive control (PC), (G3) fed on HFD with PPP free pan bread, (G4) received HFD with 2.5\% PPP fortified pan bread, (G5) received HFD with 5\% PPP fortified pan bread and (G6) fed on HFD with 7.5\% PPP fortified pan bread. Food intake, food efficiency, body weight, gain \%, epididymal adipose tissue $(\mathrm{g})$ and organs weight were recorded. Serum lipid profile and liver enzymes were analyzed. Our results showed that pomegranate peel powder $7.5 \%$ followed by $5 \%$ fortified breads reduced body weight by $(47.61 \pm 1.27 \%$ and $40.65 \pm 1.11 \%)$ respectively, compared with PC group. Total lipid, triglycerides total cholesterol, LDL-C, VLDL-C and liver functions were decreased by increasing of PPP level in pan bread while HDL-C was increased .In conclusion, our results concluded that pomegranate peel powder fortified breads with high fiber and anti- oxidative activities is recommended to gain nutritional and healthy benefits to weight loss activity and the risk of obesity.
\end{abstract}

Keywords: Obesity, Albino Rats, Pomegranate Peel Powder, Bread, Sensory Evaluation, Lipid Profile\& Liver Functions

\section{Introduction}

Overweight and obesity are defined as abnormal or excessive fat accumulation that may impair health. Around 3.4 million adults die each year as a result of being overweight or obese [1]. Obesity is one of the most common and important health concerns facing our society today. Childhood obesity affects the developed and developing countries of all socioeconomic groups irrespective of age, sex, or ethnicity [2].

According to the World Health Org., there are currently more than 1 billion overweight adults, 300 million of whom are obese [3].Weight loss in obese persons of any age can decrease the obesity-related medical complications and increase physical function and quality of life [4]. Once considered a high-income country problem, overweight and obesity are now on the rise in low- and middle-income countries.

In fact, raised body mass index (overweight and obesity) is an important cause of chronic disease, prevalence of overweight in Egypt is expected to remain relatively constant in men (69\% in 2005 and 2015$)$ and increase in women from $82 \%$ in 2005 to $84 \%$ in 2015 [5].

About $50 \%$ of the total fruits weight corresponds total peel which as important source of bioactive compounds such as phenols, flavonoids, ellagitannins and proanthocyanidin compounds that acted more dramatically in against oxidation as compared to the pulp extract [6]. Food processing by-products have become an important sanitary problem material to be studied. Such efforts have been made 
for converting these refused materials into valuable products. During processing, pomegranate peel is a major by-product which attracts attention due to its apparent wound-healing properties [7], immunomodulatory activity [8], anti-atherosclerotic and anti-oxidative capacities [9].

Bread and baked products are the most important sources of dietary fiber in the total food consumption. High fiber bread is one of the known products categorized in functional food which is health beneficial [10]. White bread has more popular because of its organoleptic properties [11]; however, there are increasing demands toward consumption of high fiber breads due to their health promoting properties. Meanwhile, utilizing some bread enhancers such as calcium propionate and proper processing can significantly improve the texture of high - fiber breads [12]. The aim of this research is to utilize pomegranate peel as a good source of fiber ingredient and antioxidant bioactive compounds in pan bead to produce value add bakery product based on pomegranate peel powder and investigation of weight loss activity of pan bread substituted with PPP as a functional food.

\section{Materials and Methods}

\subsection{Materials}

\subsubsection{Plant Material}

Ripened pomegranates (punica granatum L.) were purchased from local market at Giza, Egypt.

\subsubsection{Chemical and Kits}

Bread-making ingredients such as (wheat flour extracting rate $72 \%$, instant yeast, sugar and salt, etc), starch and oil were purchased from local market at Giza. Casein, minerals, vitamins and cellulose were purchased from El-Gomhoria Pharm and Chem. Ind. Company, Cairo, Egypt. All kits for biochemical analysis were purchased from Biodiagnostic Co., Dokki, Giza, Egypt. 1, 1-diphenyl-2-picrylhdrazylradical (DPPH) and Follin-Ciocalteus phenol reagent were purchased from Sigma-Aldrich Inc. (St.Louis, Mo, USA).All chemicals used for analysis were of analytical grade.

\subsection{Animals}

Thirty six female albino rats with average weight $180 \pm 5 \mathrm{~g}$ were obtained and housed individually in the Ophthalmology Research Institute, Giza, Egypt. The rats were kept under normal health laboratory conditions and fed on basal diet for one week (adaptation period). Water and basal diet were provided ad libitum. Basal diet composition prepared according to AIN-93M diet guidelines [13].

\subsection{Methods}

\subsubsection{Preparation of Pomegranate Peel Powder (PPP)}

Ripened pomegranates were rinsed with running tap water. The fresh peels and seeds were manually separated. Peels were cut into small pieces and dried in a fan oven at $40{ }^{\circ} \mathrm{C}$, then dried peels were powdered using a hammer mill and sieved through 40-mesh sieve. The obtained pomegranate peel powder was kept in the fridge at $-20^{\circ} \mathrm{C}$ until use.

\subsubsection{Preparation of Pomegranate Peel Fortified Pan Bread (PPB)}

The standard formula according to [14] showed in Table (1): Included $1500 \mathrm{~g}$ of wheat flour, $22.5 \mathrm{~g}$ yeast, $22.5 \mathrm{~g}$ salt $(\mathrm{NaCl})$, 45g shortining, 45g sugar ( sucrose). Three formulas were prepared with different levels of pomegranate peel powder $2.5 \%, 5 \%$ and $7.5 \%$ on wheat flour replacement basis and pure water added to make the dough. All dry ingredients were weighed and placed in a mixer for $5 \mathrm{sec}$, and then a suspension of the yeast in water was added. The mixture was further run at high speed for $92 \mathrm{sec}$ and water was added to the mixture for making the dough. The doughs were scaled into three portions, rounded into balls by hand in fermentation bowls and placed in fermentation cabinet at $30^{\circ} \mathrm{C}$ and $85 \%$ relative humidity for $20 \mathrm{~min}$. The fermented doughs were placed in pans and finally returned into the fermentation cabinet for $50 \mathrm{~min}$. The pans were placed in a convection oven at $212^{\circ} \mathrm{C}$ for $18 \mathrm{~min}$. Loaves were weighed after cooling at room temperature, sensory evaluation and the volume of loaves were recorded.

Table (1). Formulas composition of pomegranate peel pan bread

\begin{tabular}{lllll}
\hline \multirow{2}{*}{$\begin{array}{l}\text { Pan bread } \\
\text { Ingredients (g) }\end{array}$} & Control pan bread & $\mathbf{2 . 5 \%}$ & $\mathbf{5 \%}$ & $\mathbf{7 . 5 \%}$ \\
\cline { 2 - 5 } wheat flour & 1500 & 1462.5 & 1425 & 1387.5 \\
PPP & - & 37.5 & 75 & 112.5 \\
Instant yeast & 22.5 & 22.5 & 22.5 & 22.5 \\
Improver & 15 & 15 & 15 & 15 \\
Sugar & 45 & 45 & 45 & 45 \\
Salt & 22.5 & 22.5 & 22.5 & 22.5 \\
Oil & 25 & 25 & 25 & 25 \\
Shortening & 45 & 45 & 45 & 45 \\
Water & 850 & 850 & 850 & 850 \\
Total & 2525 & 2525 & 2525 & 2525 \\
\hline
\end{tabular}

\subsubsection{Chemical Composition}

Moisture, crude protein, crude fat, crude fiber and carbohydrate (by difference) of pomegranate peel powder and pan bread formulas were done according to the standard A.O.A.C. method [15]. Total phenols were estimated by the Folin-Ciocalteu method reported by [16]. The amount of total flavonoids was measured spectrophotometrically by the method according to [17]. The DPPH (2, 2-diphenyl-1-picrylhydrazyl) radical scavenging activity of methanolic extracts was determined following the method reported by [18].

The loaf volume was measured by rapeseed displacement method according to [19]. Specific volume was calculated from loaf volume and loaf weight taken after $1 \mathrm{~h}$ of baking.

\subsubsection{Texture Profile Analysis (TPA) of pan Bread}

Bread texture (firmness, cohesiveness, gumminess, chewiness, springiness and resilience) was determined using 
Texture Profile Analyzer (TPA) according to [20]. Crumb texture was determined by universal testing machine (Conetech, B type, Taiwan) provided with software. An aluminum $25 \mathrm{~mm}$ diameter cylindrical probe was used in a TPA double compression test to penetrate to $50 \%$ depth, at $1 \mathrm{~mm} / \mathrm{s}$ speed test. Texture determinations were carried out, after removing the crust, in $(40 * 40 * 30)$ mm-sized samples.

\subsubsection{Sensory Evaluation of Pan Bread}

Samples of pan bread were evaluated by 10 panelists (staff in Food Tech. Res., Institute Agric. Res. Center) for color of crust (15), color of crumb (15), taste (20), flavor (15), crumb distribution (15) and general appearance (20) . The total value of these sensory properties was evaluated as overall acceptability and descriptive category as follows: 90-100: very good 80-90: good 70-79: satisfactory: less than 70: questionable [21].

\subsection{Experimental Protocol}

Thirty-six female albino adult rats with an average weight $(180 \pm 5 \mathrm{~g})$ were obtained from animal house, Ophthalmology Research Institute, Giza, Egypt. The rats were kept under normal laboratory conditions (temperature remain $25 \pm 2^{0} \mathrm{C}$ ) for one week before the beginning of experiment ( 8 weeks). During this period, the rats were allowed free access of water and basal diet. Body weight was recorded for each rat. The basal diet prepared according to AIN- 93M diet guidelines [13], casein 14\%, soybean oil $4 \%$, salts mixture $3.5 \%$, vitamins mixture $1 \%$ and cellulose $5 \%$ and the remaining were completed with corn starch. High fat diet 30\% fat (soybean oil, 7\% and animal fat, 28\%) was prepared according to [22] and used to induce a rapid increase in body weight and obesity. Rats were randomly divided into six groups, the group one (G1) fed on basal diet and reserved as negative control. Group (2) fed on high fat diet (HFD) and reserved as positive control (PC). Groups (3-6) fed on HFD plus $30 \%$ PPP free pan bread, $30 \%$ pomegranate peel powder fortified pan bread (PPB) 2.5\%, $5 \%$ and $7.5 \%$ respectively. Each diet was prepared to give equal amount of nutritional value as control casein diet. The changes in body weight were recorded. At the end of experimental blood samples were also taken and centrifuged at $3000 \mathrm{rpm}$ for $15 \mathrm{~min}$ to obtain the serum which was kept frozen at $-20^{\circ} \mathrm{C}$ until analysis. The organs and epidermal adipose tissues were excised immediately and weighted.

Gain in body weight, food intake and food efficiency ratio were estimated according to [23].

\subsection{Biochemical Analysis of Serum}

Total lipids determined was carried out according to the method of [24].Total cholesterol, triglycerides, HDL-C were determination according to the methods of [25], [26] and [27], respectively. LDL-C and VLDL-C were calculated by using the method of [28]. Serum liver activities AST and ALT were determined according to the method of [29].

\subsection{Statistical Analysis}

Statistical analysis was carried out according to [30]. LSD (Least significant difference) test was used to compare the significant differences between means of treatment [31].

\section{Results}

\subsection{Chemical Composition of PPP, WF and Fortified Pan Bread}

Chemical composition $(\mathrm{g} / 100 \mathrm{~g})$ of pomegranate peel powder (PPP) and wheat flour is shown in Table (2). Results showed that significant increases were found in protein and carbohydrate contents for wheat flour 12.71 \pm 0.08 and $85.30 \pm 0.28$, respectively compared with pomegranate peel powder $5.76 \pm 0.076$ and $65.61 \pm 0.25$ respectively. On the contrary, significant increases were found in fat, ash and fiber contents for pomegranate peel powder $3.59 \pm 0.053$, $5.50 \pm 0.05$ and $19.54 \pm 0.16$, respectively compared with wheat flour $0.74 \pm 0.01, \quad 0.70 \pm 0.03$ and $0.55 \pm 0.26$ respectively.

Table (2). Chemical composition of pomegranate peel powder fortified pan bread.

\begin{tabular}{|c|c|c|c|c|c|c|}
\hline \multirow{2}{*}{ Chemical composition } & \multirow{2}{*}{ Wheat Flour (72\%) } & \multirow{2}{*}{ PPP } & \multirow{2}{*}{ Control bread } & \multicolumn{3}{|c|}{ PPP fortified pan bread } \\
\hline & & & & $2.5 \%$ & $5 \%$ & $7.5 \%$ \\
\hline Protein & $12.71 \pm 0.08^{\mathrm{a}}$ & $5.76 \pm 0.076^{b}$ & $13.1 \pm 0.07^{\mathrm{a}}$ & $12.89 \pm 0.08^{\mathrm{bc}}$ & $12.72 \pm 0.02^{\mathrm{cd}}$ & $12.53 \pm 0.23^{d}$ \\
\hline Fat & $0.74 \pm 0.01^{b}$ & $3.59 \pm 0.053^{\mathrm{a}}$ & $4.94 \pm 0.14^{\mathrm{d}}$ & $5.15 \pm 017 b^{c d}$ & $5.37 \pm 0.25^{\mathrm{ab}}$ & $5.6 \pm 0.11^{\mathrm{a}}$ \\
\hline Ash & $0.70 \pm 0.03^{b}$ & $5.50 \pm 0.05^{\mathrm{a}}$ & $0.95 \pm 0.081^{\mathrm{c}}$ & $1.26 \pm 0.096^{\mathrm{b}}$ & $1.35 \pm 0.04^{\mathrm{ab}}$ & $1.44 \pm 0.07^{\mathrm{a}}$ \\
\hline Fiber & $0.55 \pm 0.26^{b}$ & $19.54 \pm 0.16^{\mathrm{a}}$ & $0.59 \pm 0.03^{f}$ & $1.15 \pm 0.13^{\mathrm{c}}$ & $1.48 \pm 0.11^{b}$ & $1.71 \pm 0.059^{a}$ \\
\hline Carbohydrates & $85.30 \pm 0.28^{\mathrm{a}}$ & $65.61 \pm 0.25^{\mathrm{b}}$ & $80.42 \pm 0.14^{\mathrm{a}}$ & $79.55 \pm 0.26^{\mathrm{d}}$ & $79.08 \pm 0.18^{\mathrm{e}}$ & $78.72 \pm 0.08^{f}$ \\
\hline
\end{tabular}

Carbohydrates calculated by difference

PPP: Pomegranate Peel Powder

Chemical composition $(\mathrm{g} / 100 \mathrm{~g})$ of raw materials and pan bread formulas fortified with different levels $(2.5 \%, 5 \%$ and $7.5 \%$ ) of pomegranate peel powder are presented in Table (2). These results showed that significant decreases in protein were found in $5 \%$ and $7.5 \%$ pomegranate peel powder (PPP) fortified pan bread 12.72 \pm 0.02 and $12.53 \pm 0.23$, respectively compared with unfortified pan bread (control) 13.1 \pm 0.07 . Insignificant increase in fat content at the level of $2.5 \%$ pomegranate peel powder fortified bread $5.15 \pm 0.17$ and control bread $4.94 \pm 0.14$. 
While significant increases in fat content were found at the level of $5 \%$ and $7.5 \%$ (PPP) fortified pan bread, $5.37 \pm 0.25$ and $5.6 \pm 0.11$, respectively compared with control bread. On the other hand, significant increases $1.26 \pm 0.08,1.35 \pm 0.04$ and $1.44 \pm 0.07$ of ash content were observed at the levels of $2.5 \%, 5 \%$ and $7.5 \%$ of (PPP) fortified bread, respectively compared with unfortified bread $0.95 \pm 0.08$. Fiber content was significant increase by increasing of the level of PPP to reach to the maximum value $1.71 \pm 0.05$ at the level of $7.5 \%$ of PPP fortified bread compared with control bread $(0.59 \pm 0.03)$. On the contrary, significant decreases of carbohydrate content were observed by increasing in PPP levels to reach to the minimum value $78.72 \pm 0.08$ at $7.5 \%$ compared with unfortified bread $80.42 \pm 0.14$.

\subsection{Sensory Evaluation of Pan Bread}

Sensory properties of pan breads made from pomegranate peel powder and wheat flour as well as the $100 \%$ wheat bread are shown in Table(3). All sensory scores of color, taste, flavor, general appearance and overall acceptability were insignificantly between all fortified pan breads except 7.5\% PPP fortified bread for color of crumb (12.03 \pm 2.4$)$, color of crust $12 \pm 1.00$,general appearance $(13.31 \pm 2.8)$ and overall acceptability $(77.17 \pm 11)$ which were significantly lower than $2.5 \%(88.21 \pm 9.8)$ and $5 \%(81.9 \pm 12.74)$ PPP fortified pan bread. The control pan bread (100\% WF) recorded the highest scores for all sensory attributes compared with PPP fortified pan breads.

Table (3). Sensory evaluation of pomegranate peel powder fortified pan bread

\begin{tabular}{|c|c|c|c|c|c|c|c|c|}
\hline Pan bread & $\begin{array}{l}\text { Color of } \\
\text { Crust (15) }\end{array}$ & $\begin{array}{l}\text { Color of } \\
\text { crumb (15) }\end{array}$ & $\begin{array}{l}\text { Crumb } \\
\text { Distribution (15) }\end{array}$ & Taste (20) & Flavor (15) & $\begin{array}{l}\text { General } \\
\text { appearance (20) }\end{array}$ & $\begin{array}{l}\text { Overall } \\
\text { acceptability } \\
(100)\end{array}$ & Grade \\
\hline Control & $14.5 \pm 1.8^{\mathrm{a}}$ & $13.46 \pm 1.19^{\mathrm{a}}$ & $14.5 \pm 1.3^{\mathrm{a}}$ & $18.84 \pm 1.28^{\mathrm{a}}$ & $14.15 \pm 2.82^{\mathrm{a}}$ & $18.3 \pm 1.32^{\mathrm{a}}$ & $93.75 \pm 5.94^{\mathrm{a}}$ & Very good \\
\hline $2.5 \%$ PPP & $13 \pm 1.4^{\mathrm{a}}$ & $12.78 \pm 2.1^{\mathrm{b}}$ & $14 . \pm 1.1^{\mathrm{a}}$ & $17.51 \pm 2.25^{\mathrm{b}}$ & $13.51 \pm 2.2^{\mathrm{ab}}$ & $17.41 \pm 2.5^{\mathrm{b}}$ & $88.21 \pm 9.8^{b}$ & good \\
\hline $5 \%$ PPP & $12.5 . \pm 2.00^{\mathrm{a}}$ & $12.04 \pm 2.33^{b c}$ & $13 \pm 2^{b}$ & $16.46 \pm 2.6^{\mathrm{ab}}$ & $12.15 \pm 1.77^{\mathrm{ab}}$ & $15.38 \pm 1.8^{b c}$ & $81.9 \pm 12.74^{b c}$ & good \\
\hline $7.5 \%$ PPP & $12 \pm 1.00^{\mathrm{c}}$ & $12.03 \pm 2.4^{d}$ & $12.5 \pm 1.5^{\mathrm{b}}$ & $15.23 \pm 3.19^{b}$ & $12.00 \pm 2.43^{\mathrm{ab}}$ & $13.31 \pm 2.8^{c}$ & $77.17 \pm 11^{\mathrm{c}}$ & Satisfactory \\
\hline
\end{tabular}

\subsection{Physical Properties of Pan Breads}

Physical attributes (height, loaf weight, loaf volume, specific volume and density) of pan bread samples are given in Table (4). The results showed that PPP fortified loaves were lower in loaf volume and higher in loaf weight compared with unfortified bread (control), while the loaf volume of $7.5 \%$ PPP fortified bread was $1845 \pm 8.66$ that control was $2100 \pm 6.3$ with $12.14 \%$ reduction. On the contrary, the loaf weight of PPP fortified bread was increased by increasing in substitution of PPP to reach
$665.12 \pm 1.75$ by $7.5 \%$ substitution level compared to control bread $645.2 \pm 1.36$ by $3.09 \%$ raising. Bread specific volume decreased significantly with increasing pomegranate peel powder substitution level. The highest specific volume of bread was $3.25 \pm 0.02\left(\mathrm{~cm}^{3} / \mathrm{g}\right)$ obtained with $100 \%$ wheat flour (control). While $7.5 \%$ substitution level resulted in the lowest pan bread specific volume of $2.77 \pm 0.08\left(\mathrm{~cm}^{3} / \mathrm{g}\right)$.On the other hand, density of PPP fortified bread formulas were increased to reach $0.335 \pm 0.02$ and $0.36 \pm 0.06$ at $5 \%$ and $7.5 \%$ levels of PPP fortified bread, respectively.

Table (4). Physical properties of pomegranate peel powder fortified pan bread.

\begin{tabular}{|c|c|c|c|c|}
\hline \multirow[b]{2}{*}{ Properties } & \multirow{2}{*}{ Control bread } & \multicolumn{3}{|c|}{ PPP fortified pan bread } \\
\hline & & $2.5 \%$ & $5 \%$ & $7.5 \%$ \\
\hline Height (cm) & $8.74 \pm 0.076^{\mathrm{a}}$ & $8.40 \pm 0.1^{\mathrm{b}}$ & $7.6 \pm 0.17^{\mathrm{c}}$ & $6.4 \pm 0.24^{\mathrm{d}}$ \\
\hline Loaf weight (g) & $645.2 \pm 1.36^{\mathrm{c}}$ & $643.4 \pm 1.08^{\mathrm{c}}$ & $654.5 \pm 2.23^{b}$ & $665.12 \pm 1.75^{\circ}$ \\
\hline Loaf volume $\left(\mathrm{cm}^{3}\right)$ & $2100 \pm 6.3^{\mathrm{a}}$ & $2011.6 \pm 10.4^{\mathrm{b}}$ & $1956 \pm 5.77^{\mathrm{c}}$ & $1845 \pm 8.66^{\mathrm{d}}$ \\
\hline Specific volume $\left(\mathrm{cm}^{3} / \mathrm{g}\right)$ & $3.25 \pm 0.02^{\mathrm{a}}$ & $3.1 \pm 0.10^{\mathrm{b}}$ & $2.99 \pm 0.22^{\mathrm{c}}$ & $2.77 \pm 0.08^{\mathrm{d}}$ \\
\hline Density & $0.31 \pm 0.01^{\mathrm{d}}$ & $0.32 \pm 0.04^{\mathrm{c}}$ & $0.335 \pm 0.02^{b}$ & $0.36 \pm 0.06^{\mathrm{a}}$ \\
\hline
\end{tabular}

\subsection{Texture Profile Analysis (TPA)}

Texture profile analysis (TPA) (firmness, cohesiveness, gumminess, chewiness, springiness and resilience) is shown in Table (5). From the results in this table it could be observed that addition of PPP in formulation of pan bread samples significantly affected the textural properties of the breads. Firmness, cohesiveness, gumminess, springiness and resilience of pan bread samples were significantly $(\mathrm{p}<$ 0.05 ) decreased by increasing of PPP level in their formulas from $2.72 \pm 0.07,0.94 \pm 0.03,1.25 \pm 0.05,1.45 \pm 0.02$ and $0.44 \pm 0.03$ respectively, for bread control to $2.18 \pm 0.08$, $0.49 \pm 0.04,0.74 \pm 0.02,0.76 \pm 0.02$ and $0.16 \pm 0.01$ respectively in $7.5 \%$ PPP bread formula. On the contrary, chewiness was significantly $(p<0.05)$ increased by increasing of PPP level in their formula from $5.61 \pm 0.01$ for bread control to $8.32 \pm 0.02$ in $7.5 \%$ PPP pan bread formula. Level of $2.5 \%$ and 5\% PPP pan bread formulas were better than 7.5\% PPP pan bread formula for texture profile properties. 
Table (5). Texture profile analysis (TPA) of pomegranate peel powder fortified pan bread

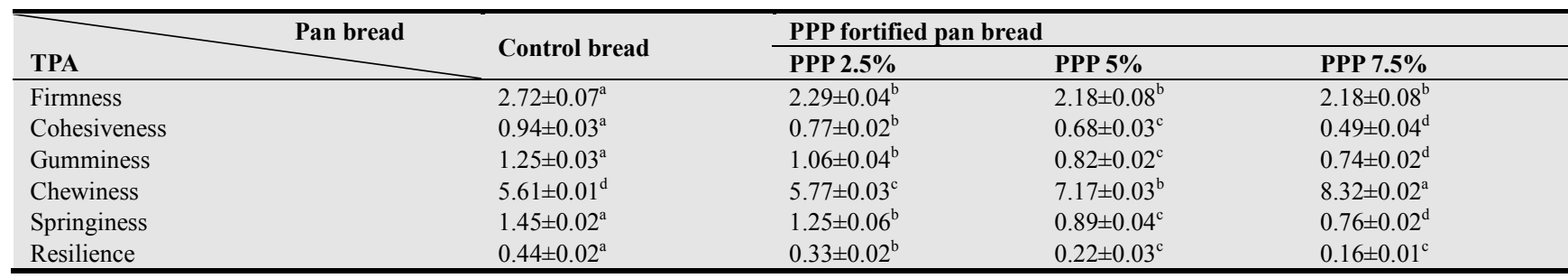

\subsection{Total Phenolic Contents, Total Flavonoids and DPPH}

Total phenolic contents, total flavonoids and DPPH radical scavenging activity of PPP and pan bread are presented in Table (6). Total phenols and flavonoids were expressed as $\mathrm{mg}$ gallic acid/gm and $\mathrm{mg}$ quercetin /gm of dry weight, respectively, while DPPH was expressed as inhibition percent. From the data presented in Table (6) it could be noticed that, the pomegranate peel powder is a good source of total phenolic content $116.75 \pm 2.72$, total flavonoids $50.06 \pm 1.14$ and had a great free radical scavenging activity (DPPH) $88.88 \%$.Substitutiion of wheat flour with $2.5 \%, 5 \%$ and $7.5 \%$ of PPP for making pan breads resulted in significant increases in total phenolics, flavonoids and DPPH respectively. PPP (7.5\%) substituted pan bread characterized with the highest values of total phenolic contents $5.24 \pm 0.96 \mathrm{mg} \mathrm{GAE} / \mathrm{g} \mathrm{DW}$, total flavonoids, $3.17 \pm 0.2 \mathrm{mg}$ Que/g DW and DPPH, $77.58 \%$ respectively compared with control bread $(100 \%$ wheat flour). While PPP (5\%) substituted bread recorded $3.53 \pm 0.44 \mathrm{mg} \mathrm{GAE} / \mathrm{g} \mathrm{DW}, 1.83 \pm 0.12 \mathrm{mg}$ Que $/ \mathrm{g}$ DW and $63.9 \%$ for total phenolics, total flavonoids and DPPH (\%) respectively.

Table (6). Total Phenols (TP), Total Flavonoids (TF) and DPPH \% pomegranate peel powder fortified pan bread

\begin{tabular}{llll}
\hline \multirow{2}{*}{ Pan bread } & Total Phenols(TP) & Total Flavonoids (TF) & DPPH \\
\cline { 2 - 4 } & mg GAE/g & mg Que/g & \% \\
\hline PPP & $116.75 \pm 2.72^{\mathrm{a}}$ & $50.06 \pm 1.14^{\mathrm{a}}$ & $88.88 \pm 0.71^{\mathrm{a}}$ \\
Control & $0.79 \pm 0.08^{\mathrm{d}}$ & $0.06 \pm 0.017^{\mathrm{d}}$ & $29.02 \pm 1.24^{\mathrm{e}}$ \\
$2.5 \%$ & $2.26 \pm 0.72^{\mathrm{c}}$ & $0.95 \pm 0.13^{\mathrm{cd}}$ & $44.52 \pm 0.51^{\mathrm{d}}$ \\
$5 \%$ & $3.53 \pm 0.44^{\mathrm{c}}$ & $1.83 \pm 0.12^{\mathrm{c}}$ & $63.9 \pm 1.12^{\mathrm{c}}$ \\
$7.5 \%$ & $5.24 \pm 0.96^{\mathrm{b}}$ & $3.17 \pm 0.2^{\mathrm{b}}$ & $77.58 \pm 1.5^{\mathrm{b}}$ \\
\hline
\end{tabular}

PPP: Pomegranate Peel Powder

GAE: gallic acid equivalents; Que: Quercetin equivalent.

\subsection{Body Weight, Gain, Food Intake and Epididylmal Adipose Tissue}

Body weight changes, gain, food consumption and food efficiency ratio are presented in Table (7). The results indicated that the rats fed on high fat diet had significant increase in food consumption, food efficiency ratio and gain body weight compared with the others fed on basal diet (Negative control).The rats fed on PPP fortified pan bread formulas resulted in significant decrease in food intake, food efficiency and body weight gain compared with the others fed on high fat diet (PC) and control bread .G.B.W\% and epididymal adipose tissue of rats fed on 5\% and $7.5 \%$ PPP fortified pan bread diets were $(47.61 \pm 1.27 \%$ and $40.65 \pm 1.11 \%)$ and $(10.77 \pm 0.93,9.063 \pm 0.43)$ lower than unfortified bread diet and high fat diet free bread. The pomegranate peel powder substitution of wheat flour for making pan bread had a powerful antioxidant activity and weight loss effects.

Table (7). Body weight (gm), gain\%, food intake (gm) and food efficiency ratio of rats fed on pomegranate peel powder fortified pan bread.

\begin{tabular}{|c|c|c|c|c|c|c|}
\hline Groups & $\mathrm{NC}$ & PC & Control bread & $2.5 \%$ & $5 \%$ & $7.5 \%$ \\
\hline Initial & $177.92 \pm 2.24^{\mathrm{a}}$ & $176.4 \pm 4.1^{\mathrm{a}}$ & $178.2 \pm 3.01^{\mathrm{a}}$ & $179.3 \pm 1.03^{\mathrm{a}}$ & $178.6 \pm 3.1^{\mathrm{a}}$ & $177.5 \pm 3.5^{\mathrm{a}}$ \\
\hline Final weight & $242.4 \pm 3.1^{\mathrm{e}}$ & $295.1 \pm 3.8^{\mathrm{a}}$ & $276.3 \pm 3.4^{\mathrm{ab}}$ & $272.7 \pm 1.9^{\mathrm{b}}$ & $263.6 \pm 2.2^{c}$ & $249.8 \pm 2.9^{\mathrm{d}}$ \\
\hline Body gain & $64.45 \pm 0.96^{\mathrm{f}}$ & $118.7 \pm 1.45^{\mathrm{a}}$ & $98.16 \pm 1.23^{\mathrm{b}}$ & $93.41 \pm 1.12^{\mathrm{c}}$ & $85.00 \pm 0.97^{\mathrm{d}}$ & $72.23 \pm 0.59^{\mathrm{e}}$ \\
\hline Food intake & $946.8 \pm 5.6^{\mathrm{c}}$ & $992.1 \pm 5.8^{\mathrm{a}}$ & $1002.4 \pm 4.6^{\mathrm{a}}$ & $965.1 \pm 11.7^{\mathrm{b}}$ & $957.6 \pm 9.7 b^{c}$ & $939.9 \pm 4.3^{d}$ \\
\hline Food Efficiency ratio & $6.81 \pm 0.1^{\mathrm{d}}$ & $10.39 \pm 0.24^{\mathrm{a}}$ & $9.98 \pm 0.39^{\mathrm{a}}$ & $9.72 \pm 0.11^{\mathrm{ab}}$ & $9.17 \pm 0.47^{b}$ & $8.06 \pm 0.65^{\mathrm{c}}$ \\
\hline Body gain \% & $36.22 \pm 0.24^{\mathrm{f}}$ & $67.29 \pm 1.3^{\mathrm{a}}$ & $55.1 \pm 1.15^{\mathrm{b}}$ & $52.11 \pm 0.51^{\mathrm{c}}$ & $47.61 \pm 1.27^{\mathrm{d}}$ & $40.65 \pm 1.11^{\mathrm{e}}$ \\
\hline Epididymal adipose tissue(g) & $6.953 \pm 0.49^{\mathrm{e}}$ & $15.73 \pm 0.34^{\mathrm{a}}$ & $14.22 \pm 0.66^{\mathrm{b}}$ & $11.77 \pm 0.40^{\mathrm{c}}$ & $10.77 \pm 0.93^{c}$ & $9.063 \pm 0.43^{\mathrm{d}}$ \\
\hline Relative liver weigh (gm) & $1.30 \pm 0.1^{\mathrm{c}}$ & $2.2 \pm 0.25^{\mathrm{a}}$ & $1.42 \pm 0.06 b^{c}$ & $1.45 \pm 0.15 b^{c}$ & $1.51 \pm 0.05^{\mathrm{b}}$ & $1.60 \pm 0.12^{\mathrm{b}}$ \\
\hline Relative heart weigh (gm) & $0.21 \pm 0.03^{\mathrm{b}}$ & $0.32 \pm 0.05^{\mathrm{a}}$ & $0.24 \pm 0.02^{\mathrm{b}}$ & $0.20 \pm 0.04^{\mathrm{b}}$ & $0.22 \pm 0.02^{\mathrm{b}}$ & $0.24 \pm 0.06^{\mathrm{b}}$ \\
\hline
\end{tabular}

\subsection{Relative Organs Weight}

Relative organs weight of (liver and heart) are shown in Table (7). The results showed that, there is significant increase in these relative organs weight of the rats fed on high fat diet (HFD) free pan bread compared with the rats fed on basal diet or PPP fortified pan bread diets. Insignificant differences were found between the organs weight of rats fed on high fat diets containing PPP fortified pan bread fortified. 


\subsection{Lipid Profile}

Serum lipid profile in rats fed on HFD and HFD containing PPP fortified pan breads are presented in Table(8).

Serum total lipids, triglycerides, total cholesterol, LDL-C and VLDL-C were significantly $(\mathrm{p}<0.05)$ higher in rats fed on HFD ( positive control )group, $581.4 \pm 0.95,245.8 \pm 0.56$, $170.3 \pm 1.86,99.52 \pm 0.81$ and $49.15 \pm 0.11$, respectively while HDL-C was significantly lower $(21.57 \pm 1.01)$ than negative group. Diets contained PPP fortified pan breads significantly decreased for the previous parameters particularly, $7.5 \%$ PPP fortified bread which were $442.3 \pm 1.67,141.9 \pm 1.51$, $85.68 \pm 0.62, \quad 13.82 \pm 0.84, \quad 28.39 \pm 0.31, \quad$ respectively. Significant reduction of HDL-C (48.36\%) was observed in rats fed on HFD (PC) compared to the others fed on basal diets (NC). On the other hand significant reductions $(19.02 \%)$ and $(23.92 \%)$ of total lipid were observed in rats fed on $5 \%$ and $7.5 \%$ PPP fortified pan breads respectively.

Table (8). Lipid profile of rats fed on PPP fortified pan bread.

\begin{tabular}{|c|c|c|c|c|c|c|}
\hline $\begin{array}{l}\text { Parameter } \\
\text { Groups }\end{array}$ & $\begin{array}{l}\text { Total lipid } \\
(\mathrm{mg} / \mathrm{dl})\end{array}$ & $\begin{array}{l}\text { Triglycerides } \\
(\mathrm{mg} / \mathrm{dl})\end{array}$ & $\begin{array}{l}\text { Total cholesterol } \\
(\mathrm{mg} / \mathrm{dl})\end{array}$ & $\begin{array}{l}\text { HDL-C } \\
(\mathrm{mg} / \mathrm{dl})\end{array}$ & $\begin{array}{l}\text { LDL-C } \\
(\mathrm{mg} / \mathrm{dl})\end{array}$ & $\begin{array}{l}\text { VLDL-C } \\
(\mathrm{mg} / \mathrm{dl})\end{array}$ \\
\hline $\mathrm{NC}$ & $412.1 \pm 1.07^{\mathrm{f}}$ & $124.2 \pm 0.95^{\mathrm{f}}$ & $90.32 \pm 1.19^{\mathrm{e}}$ & $41.77 \pm 1.06^{\mathrm{a}}$ & $23.72 \pm 0.34^{\mathrm{e}}$ & $24.83 \pm 0.19^{f}$ \\
\hline $\mathrm{PC}$ & $581.4 \pm 0.95^{\mathrm{a}}$ & $245.8 \pm 0.56^{\mathrm{a}}$ & $170.3 \pm 1.86^{\mathrm{a}}$ & $21.57 \pm 1.01^{\mathrm{e}}$ & $99.52 \pm 0.81^{\mathrm{a}}$ & $49.15 \pm 0.11^{\mathrm{a}}$ \\
\hline Control bread & $562.1 \pm 1.48^{\mathrm{b}}$ & $231.3 \pm 0.93^{b}$ & $155.9 \pm 1.35^{\mathrm{b}}$ & $29.49 \pm 1.21^{\mathrm{d}}$ & $80.19 \pm 0.24^{b}$ & $46.25 \pm 0.18^{b}$ \\
\hline $2.5 \%$ & $527.1 \pm 1.71^{\mathrm{c}}$ & $211.6 \pm 1.21^{\mathrm{c}}$ & $132.6 \pm 1.24^{\mathrm{c}}$ & $31.41 \pm 0.39^{c}$ & $58.89 \pm 0.96^{\mathrm{c}}$ & $42.33 \pm 0.24^{\mathrm{c}}$ \\
\hline $5 \%$ & $470.8 \pm 0.83^{\mathrm{d}}$ & $170.7 \pm 1.75^{\mathrm{d}}$ & $100.5 \pm 1.39^{\mathrm{d}}$ & $35.50 \pm 0.39^{\mathrm{b}}$ & $30.72 \pm 1.21^{\mathrm{d}}$ & $34.14 \pm 0.35^{\mathrm{d}}$ \\
\hline $7.5 \%$ & $442.3 \pm 1.67^{\mathrm{e}}$ & $141.9 \pm 1.51^{\mathrm{e}}$ & $85.68 \pm 0.62^{f}$ & $43.47 \pm 1.15^{\mathrm{a}}$ & $13.82 \pm 0.84^{\mathrm{f}}$ & $28.39 \pm 0.31^{\mathrm{e}}$ \\
\hline
\end{tabular}

\subsection{Liver Functions}

Table (9) shows the estimated levels of serum AST, ALT in control and various experimental group of rats. Serum AST, ALT levels in high fat diet fed rats were highly significant when compared with the corresponding control rats. Administration of pomegranate peel powder pan breads to high fat diet fed rats caused marked reduction in the elevated activities of AST, ALT towards the normal values.

Table (9). Liver functions of rats fed on PPP fortified pan bread.

\begin{tabular}{lll}
\hline Parameter groups & AST $(\mathbf{U} / \mathbf{L})$ & ALT(U/L) \\
\hline $\mathrm{NC}$ & $26.36 \pm 0.28^{\mathrm{e}}$ & $19.55 \pm 0.95^{\mathrm{e}}$ \\
$\mathrm{PC}$ & $88.19 \pm 1.25^{\mathrm{a}}$ & $61.77 \pm 1.21^{\mathrm{a}}$ \\
Control & $76.01 \pm 1.57^{\mathrm{b}}$ & $56.94 \pm 1.65^{\mathrm{b}}$ \\
$2.5 \%$ & $67.72 \pm 0.57^{\mathrm{b}}$ & $52.85 \pm 0.44^{\mathrm{b}}$ \\
$5 \%$ & $56.55 \pm 1.21^{\mathrm{c}}$ & $48.31 \pm 0.65^{\mathrm{c}}$ \\
$7.5 \%$ & $42.68 \pm 0.96^{\mathrm{d}}$ & $30.30 \pm 0.38^{\mathrm{d}}$ \\
\hline
\end{tabular}

\section{Discussion}

At the present time, functional foods, which in principle apart from their basic nutritional functions provide physiological and healthy benefits and are very important [32]. There has been a virtual explosion of interest in the pomegranate as medicinal and nutritional product because of its multifunction ability and its great benefit in the human. Our results showed that chemical composition of wheat flour and pomegranate peel powder confirmed those obtained by [33]. Who found that wheat flour $(72 \%$ extraction) contained $13.19 \%, 1.24 \%, 0.56 \%, 0.68 \%$ and $84.38 \%$ protein, lipids, fiber, ash and carbohydrates, respectively. Concerning pomegranate peel powder, it contained $5.76 \pm 0.076,3.59 \pm 0.053,5.50 \pm 0.045,19.54 \pm 0.16$ and $65.61 \pm 0.25$ for protein, fat, ash, fiber and carbohydrates, respectively. These results in the line of [34]. Significant and insignificant changes in (protein, fat, ash, fiber and total carbohydrates of pomegranate peel powder substituted pan bread samples at $2.5 \%, 5 \%$ and $7.5 \%$ level may be due to changes in chemical composition of wheat flour and pomegranate peel powder.

Pomegranate peel powder substituted pan bread increased loaf weight these may be due to presence of hydrocolloids (pectin) in the pomegranate peel powder; meanwhile the reduction of loaf volume could be due to the reduction of dough gas retention power [35]. Our results agree with [36] who reported that hydrocolloids, commonly can bind as 100 times of their weight from water. Gluten is responsible for increase in bread volume and partial replacement of wheat flour with non-glutinous flour results in lower bread volume [37], also bread supplemented with different dietary fibers had decrease in loaf volumes [38]. Specific volume is directly related to loaf volume hence an expected decrease in specific volume was observed while density is inversely decreased significantly with substitutions. Density reflects the size and ratio of air cells to solid product. A similar trend in physical attributes was observed by [38] who suggested that it could be probably due to higher water absorption capacity in non-gluten flour thus it contributed in higher density. Our results agree with [39] who reported that, partial substitution of wheat flour with some grains such as barely, cellulose and oat caused a reduction in volume of loaves of bread this could be due to gluten dilution and consequently, affect the optimal gluten matrix formation during the mixing, fermentation, and baking steps.

Recently, natural antioxidants have become very popular for medical and food applications and are preferred by consumers than synthesized antioxidants. Oxidation leads to a significant loss of a foods nutritional value (vitamins and essential fatty acids). It also affects the food sensory quality changes in color, texture and taste which shorten its shelf life and can results in rejection by consumers [40]. The antioxidant activity of pomegranate peel components has 
been the subject of many studies [41]. All these activities may be related to the diverse phenolic and flavonoids compounds presence in pomegranate peel.

Our results indicated that total phenolic, total flavonoids and DPPH increased of substituted pan bread by increasing of substitution levels. This could be due to pomegranate peel powder contains phenols and flavonoids more than wheat flour, subsequently increase DPPH of substituted pan bread formulas. These results in the line of [42] who found that the amount of total phenols was $124.34 \mathrm{mg} \mathrm{GAE} / \mathrm{g}$ and [43] who reported that total phenols was $64.2 \mathrm{mg} \mathrm{GAE} / \mathrm{g} \mathrm{dw}$. by $\mathrm{MeoH}$ extraction, total phenols was $85.6 \mathrm{mg} \mathrm{GAE} / \mathrm{g} \mathrm{dw}$ [44] According to condition of extraction [45], reported that methanol $(\mathrm{MeoH})$ extract of pomegranate peel exhibit $81 \%$ free radical scavenging activity and [6] reported that pomegranate peel contains flavonoid higher than the pulp (59 vs. $17 \mathrm{mg} / \mathrm{g}$ ).

The replacement of wheat flour with pomegranate peel powder significant increased chewiness (the energy required to chew a solid food into a state for swallowing) this could be due to attributed to change in protein quantity, quality and water absorption. Firmness, cohesiveness, gumminess, springiness and resilience were significantly decreased at the high level of substitution of pomegranate peel powder could be due to decrease in gluten forming proteins and increase in dietary fiber contents contributed by pomegranate peel powder which affected the formation of gluten network. Springiness of the bread samples were significantly reduced by high addition of PPP in their formulation, interaction between gelatinized starch and gluten dough which cause dough to be more elastic can form continuous sponge structure of bread after heating [46]. Lower amount of gluten cause lower ability to hold gases which caused an elasticity reduction in breads. The reduction of cohesiveness could be the bread formulated with PPP has low ability to resist before the bread structure deformed under the teeth. These results agree with [14] who found that the replacement of wheat flour with sorghum flours decreased cohesiveness and resilience in bread samples, particularly at the high level of substitution and reported that the bread required more time to recover its shape after stress. Pan bread formulated 2.5\% and 5\% PPP were better for TPA than $7.5 \%$ level of substitution.

Color of bread is one of the important factors in sensory evaluation [47] depending on their perception of bread type. The color of bread was changed and become whiter by increasing levels of starch in the formula. Because of browning of regular baked products depends to a large of the presence protein. So the bread samples with high level of fiber content, low protein and starch have darker color and negative effect on consumers overall acceptability [35], in this line [48] found that the addition of apple pectin extract at $2 \%$ dry matter to wheat dough increased intensity of crust browning and gave darker and soft crumb compared with untreated bread. The control pan bread (100\% w f) recorded the highest scores for all sensory attributes compared with PPP fortified pan bread.

Pan bread samples substituted with $2.5 \%$ and $5 \%$ PPP had higher scores of color, general appearance and overall acceptability for panelists. The breads with PPP substitution will be superior in nutritional quality and provide more health benefits. Taste scores decreased significantly as the level of PPP increased 7.5\% may be due to slight better of phenolics and tannins compounds. The sensory properties of pan breads made from pomegranate peel powder and wheat flour as well as the $100 \%$ wheat bread are shown in Table (6). All sensory score ( color, taste , flavor , texture , general appearance and overall acceptability) were insignificantly in all blends pan bread except 7.5\% PPP fortified bread for color $(12.53 \pm 2.4)$ general appearance $(13.31 \pm 2.8)$ and overall acceptability $(70.08 \pm 11)$ which were significantly lower than 2.5\% and 5\% PPP fortified pan bread.

Obesity is characterized by increased adipose tissue mass that results from both increased fat cell number and increased fat cell size. Adipose tissue is a dynamic organ that plays an important role in energy balance and changes in mass according to the metabolic requirements of the organism [49]. ]. In our results, the weight of epididymal adipose tissue in pomegranate peel fortified pan bead treated groups was significantly decreased compared to the HFD-control group. These results suggest that pomegranate peel fortified pan bead may prevent the accumulation of white adipose tissue (WAT) in HFD-induced obese rats or anti-obesity effects of pomegranate peel bioactive compounds may be elicited by regulating the expressions of lipogenesis-related genes in WAT. [50], Investigated the effects of pomegranate extract (6\% punicalagin) in female rats following exposure to a diet containing $20 \%$ of the extract for $37 \mathrm{~d}$. The exposure to pomegranate extracts result in an intake of $4800 \mathrm{mg}$ punicalagin $/ \mathrm{kg} / \mathrm{d}$. A significant decrease in feed consumption and body weight of the animals. PPP had beneficial effects on reduction of body weight, and fat accumulation through controlling in hormones related obesity (Leptin-a diponectin pathway), high concentration of tannin may reduce intake, digestibility of protein and carbohydrates, and animals performance through their negative effect on palatability and digestion [51]. Inhibiting the absorption of dietary TG may play an important role on weight loss because an excessive intake of TG from the diet is relevant to the development of obesity.

Our, results agree with [52] who found that pomegranate juice and molasses antioxidants activity induced weight loss in the animals. Hypercholesterolemic rats administrated with different levels of pomegranate peel powder had significant decrease in food consumption and body weight gain ratio [53]. Significant increase in organs of rats which fed on HFD (positive control), on the other hand significant decrease were occurred in liver, heart to body weight ratio of rats fed on diet containing different levels of PPP fortified pan bread, these results agree with [53] who found that pomegranate peels powder significant decreased weight organs of rats near the normal values. It has been clinically reported that the pancreatic lipase inhibitor orlistat prevented obesity and hyperlipidemia by decreasing the absorption of dietary fat into blood and increasing the fat 
excretion in feces [54].

Pomegranate peel powder fortified breads and its compounds, phenolics and flavonoids, may be a significant effect on inhibiting the pancreatic lipase activity and increasing the fecal fat excretion, which suggests that it is one of the mechanisms responsible for decreasing the serum TG concentrations and transforms VLDL-C into LDL-C.

Increment of plasma LDL-C level after HFD consumption could be explained via involvement of two enzymes namely cholesterol ester hydrolase $(\mathrm{CEH})$ and cholesterol ester synthetase (CES). These enzymes balance the cholesterol levels in the blood [55]. Phenols and flavonoids are very important plant constituents because of their antioxidant activity [42]. Pomegranate juice is rich in polyphenols and demonstrates high capability in scavenging free radicals and inhibiting LDL-c oxidation in vitro and in vivo [56].

Higher activities of these enzymes in serum have been found in response to oxidative stress induced by high fat diets [57]. In our study these parameters were significantly enhanced by the high fat diet, suggesting that excessive fat intake might cause critical injury to the organ due to the over-production of free radicals and ROS, which exert deleterious effects on liver. Rats fed diet-induced obesity models showed an increase in the levels of oxidative stress in their liver and that oxidative stress can result from the excessive production of reactive oxygen species and/or deficient antioxidant capacity [58]. In our study, because the strong antioxidant activity of pomegranate peel powder fortified bread (rich in total phenolic and flavonoids compounds) secretion of AST, ALT were regulated and the liver was protected from toxicity of feeding on HFD.

\section{Conclusion}

In conclusion, the results suggested that pomegranate peel powder fortified pan bread with high fiber and anti oxidative activities is recommended to considered hypolipidemic diet, nutritional and healthy benefits to weight loss activity and the risk of obesity with acceptable physical and sensory quality.

\section{References}

[1] W. H. O., (2014) Obesity and overweight. Available at:http:www.who.int/mediacentre/factsheets/fshyperlink.

[2] Raj, M. and Kumar, R.K. (2010) Obesity in children \& adolescents. Indian. J Med Res; 132:598-607.

[3] Mackay, J. and Mensah, G. (2004) The atlas of heart disease and stroke. Geneva,Switzerland: World Health Org.

[4] Yuliana, N.D.; Jahangir, M.; Korthout, H.; Choi, Y.H. ; Kim, H.K. ; Verpoorte, R(2011) Comprehensive review on herbal medicine for energy intake suppression. Obes $\operatorname{Rev} ; 2: 499-514$.

[5] W.H.O., (2005) The impact of chronic disease in Egypt www.who.int/chp/chronic_dichronicdisease.../impact/egypt
[6] Li, Y. ; Guo, C. ; Yang, J. ; Wei, J. ; Xu, J. ; Cheng, S. (2006) Evaluation of antioxidant properties of pomegranate peel extract in comparison with pomegranate pulp extract. Food Chem., 96:245-260.

[7] Chidambara, M.K.N. ; Reddy, V.K. ; Veigas, J.M. and Murthy, U.D.(2004) Study on wound healing activity of Punica granatum peel. J.Med. Food, 7: 256-259.

[8] Gracious, R.R. ; Selvasubramanian, S. and Jayasundar, S. ( 2001) Immunomodulatory activity of Punica granatum in rabbits -a preliminary study. J.Ethnopharmacol. 78: 85-87.

[9] Tzulker, R. ; Glazer, I. ; Bar-Ilan, I. ; Holland, D. ; Aviram, M. and Amir, R. (2007) Antioxidant activity, polyphenol content, and related compounds in different fruit juices and homogenates prepared from 29 different pomegranate accessions. J. Agr. Food Chem., 55: 9559-9570

[10] Galisteo, M. ; Duarte, J. and Zarzuelo, A. (2008) Effects of dietary fibers on disturbances clustered in the metabolic syndrome. Journal of Nutritional Biochemistry 19: 71-75.

[11] Ingram, C. and Shapter, S. ( 2006) Bread. Anness Publishing, Dewey Edition .

[12] Stanley, P. C. and Linda, S. Y.( 2006) Baked products: Science, technology and practice. Blackwell Publishing Ltd. 36-37.

[13] Reeves, P. G. ; Nielsen, F. H. ; and Fahey, G. C. JR. (1993) AIN-93 Purified Diets for Laboratory Rodents: Final Report of the American Institute of Nutrition Ad. Hoc Writing Committee on the Reformulation of the AIN-76A Rodent Diet J. Nutr. 123: 1939-1951.

[14] Abdelghafor ,R.F. ; Mustafa ,A.I. ; Ibrahim ,A.M.H. and Krishnan, P.G.(2011) Quality of bread from composite flour of sorghum and hard white winter wheat. Advance Journal of Food Science and Technology 3(1): 9-15.

[15] A. O. A. C. (2000). Official methods of Analysis of Association of Official Analytical Chemists. edited B, Kenesseth Helrick. Fifteenth Edition.

[16] Elfalleh, W. ; Nasri, N. ; Marzougui, N. ; Thabti, I. ; Rabet, A. ; Yayia, Y. ; Lachiheb, B.; Guasmi, F. and Ferchichi, A. (2009). Physico-chemical properties and DPPH-ABTS scavenging activity of somelocal pomegranate (Punica granatum) ecotypes. J. Food Sci. Nutr., 60: 925-938.

[17] Nasri, N. ; Tlili, N. ; Ellfalleh, W. ; Emna, C. ; Ferchichi, A. ; Khaldi, A. and Saida, T. (2011) Chemical compounds from phoenician juniper berries (Juniperus phoenicea). Natural Product Research, 25:1733-1742.

[18] Okonogi, S. ; Duangrat, C. ; Anuchpreeda,S. ; Tachakittirungrod, S. and Chowwanapoonpohn, S. (2007) Comparison of antioxidant capacities and cytotoxicities of certain fruit peels. Food Chemistry, 103: 839-846.

[19] A.A.C.C. (1990) Approved method of American Association of Cereal Chemists published by American Association of Cereal Chemists. Ins., St. Paul, Minnesota, U.S.A.

[20] Bourne, M. C. (2003) Food texture and v cosity: concept and measurement. Elsevier Press, New York/London.

[21] Khorshid,Ahmed M. ;Nadia H.A. ; Assem, Nadia M.Abd-EL-Motaleb and Jermine, S. Fahim. (2011) Utilization of flaxseeds in improving bread quality. Egypt. J. Agric. Res., 89 (1). 
[22] Santos ,B. d. ; Estadella ,D. ; Hachul ,A. C. L ; Okuda ,M.H. ; Moreno ,M.F. ; Oyama, L.M. ; Ribeiro ,E.B. and Nascimento, C.M.P. O. (2013) Effects of a diet enriched with polyunsaturated, saturated,or trans fatty acids on cytokine content in the liver, white adipose tissue, and skeletal muscle of adult mice. Mediators of Inflammation,1-10. http://dx.doi.org/10.1155/2013/594958

[23] Chapman, D. G. ; Castillo, R. and Campbell, J. A. (1959) Evaluation of protein in food.I..A. Method for the determination of protein efficiency ratio. Can. J. Biochem. Physiol., 37, 679.-686.

[24] Zollner,N. and Kirsh,K.Z.(1962) Colorimetric method for determination of total lipid in serum.Ges.Exp.Med.,135:545

[25] Allain,C.; Poon,L. and Chan,C. (1974) Enzymatic determination of serum total cholesterol. Clin. Chem.; 20: $470-475$.

[26] Fassati,P. and Prencipe,1. (1982) Triglycerides determination after enzymatic hydrolysis. Clin.chem., 28:2077.

[27] Lopez- Virella, M. F.; Stone, S.; Eills, S. and Collwel, J. A. (1977) Determination of HDL-cholesterol using enzymatic method. Clin.Chem., 23:882.

[28] Friedwold,W.; Leve,R. and Fredrickson,D.(1972)Estimation of the concentration of low denisty lipo protein separated by three different methods. Clin. Chem.; 18: 499-502.

[29] Reitman, S. and Frankel, S. (1957) A calorimetric method for the determination of glutamic oxalacetic and glutamic pyruvic transaminase.Amer. J. Clin. Path., 28: 56 - 63.

[30] Fisher, R. A. (1970). Statistical Method for Research Workers, Eds. Oliver and Boyed, Edinburgh, pp. 140-142.

[31] Waller, W. M. and Duncan, D. B. (1969). A Bayes rule for the symmetric multiple comparison problem. J. Am. Statistical Assoc., 64:1484-1499.

[32] Viuda-Martos, M. ; Lopez-Marcos, M.C. ; Fernandez-Lopez, J. ; Sendra, E. ;Sayas-Barbera, E. ; Lopez-Vargas, J.H. ; Perez-Alvarez, J.A.( 2010) The role of fiber in cardiovascular diseases: a review. Comp. Rev. Food Sci. and Food Safety 9:240-58.

[33] El-Badrawy, A. K. (1994) Utilization of refused bread in Egyptian Bread Making. M.Sc., Thesis. Faculty of Agric. Cairo University. Egypt.

[34] Shabtay ,A. ; Eitam, H. ; Tadmor ,Y. ; Orlov ,A. ; Meir ,A. ; Weinberg, ,P. ; Weinberg ,Z.G. ; Chen ,Y. ; Brosh ,A. ; Izhaki, I. and Kerem, Z. (2008) Nutritive and antioxidative potential of fresh and stored pomegranate industrial byproduct as a novel beef cattle feed. J. Agric. Food Chem. 2008, 56, 10063-10070.

[35] Yaseen, A.A. ; Shouk,A.A. ; Enssaf, M.A El-Hamzy and Ashour, M.M.S.. (2012) Production and evaluation of low phenylalanine pan bread. Journal of Applied Sciences Research, 8(12): 5799-5805.

[36] Ward, F. M. (1997) Hydrocolloids system as fat mimics in bakery products, glazes and Fillings. Cereal Food World, 42:386-390.

[37] Banks, W.T. ; Wang, C. and Susan, M. (1997) Partially De-oiled soy flour effects on sensory and physical characteristics of baked products. Journal ofConsumer Studies \& Home Economics 21: 151-156.
[38] Siddiq, M. ; Nasir, M. ; Ravi, R. ; Dolan, K.D. and Butt, M.S.(2009) Effect of De-oiled maize germ addition on the functional and textural properties of wheat flour. International Journal of Food Properties 42: 462-470.

[39] Ragaee, S. ; Guzar, I. ; Dhull, K. and Seetharaman, K. (2011) Effects of fiber addition on antioxidant capacity and nutritional quality of wheat bread. Journal of food Science and Technology, 44, 2147-2153.

[40] Fernández-López,J. ; Viuda-Martos, M. ; Sendra, E. ; Sayas-Barberá, E. ;Navarro, C. and Pérez-Alvarez, J.A.( 2007) Orange fiber as potential functional ingredient for dry-cured sausages. Eur. Food Res. Technol. 226(1-2):1-6.

[41] Tezcan, F. ; Gültekin-Özgüven, M. ; Diken, T. ; Özçelik, B. and Erim, F.B. (2009) Antioxidant activity and total phenolic, organic acid and sugar content in commercial pomegranate juices. Food Chem. 115(3):873-7.

[42] Abdel- Moneim,A. E.(2012) Antioxidant activities of Punica granatum (pomegranate) peel extract on brain of rats. Journal of Medicinal Plants Research Vol. 6(2): 195-199

[43] Al-Rawahi,A.S. ; Edwards, G. ; Al-Sibani, M. ; Al-Thani, G. ; Al-Harrasi,A.S. and Rahman, M. S.( 2014) Phenolic Constituents of Pomegranate Peels (PunicagranatumL.) Cultivated in Oman. European Journal of Medicinal Plants $4(3): 315-331$

[44] Elfalleh,W. ;Hannachi,H. ;Tlili,Z. ;Yahia,Y. ; Nasri ,N. and Ferchichi,A.(2012) Total phenolic contents and antioxidant activities of pomegranate peel, seed, leaf and flower. Journal of Medicinal Plants Research Vol. 6(xx), pp. 4724-4730.

[45] Singh,R. P. ; Chidambara Murthy ,K. N. and Jayaprakasha, G. K.( 2002) Studies on the Antioxidant Activity of Pomegranate (Punica granatum) Peel and Seed Extracts Using in Vitro Models. J. Agric. Food Chem., 50 (1), 81-86.

[46] Hoseney, R. C. (1994) Principles of Cereal science and technology. 3rd edition, United Kingdom: American association of cereal chemists, Inc. P. 203-206.

[47] Matos, M. and Rosell., C. (2012) Quality Indicators of Rice-Bas Gluten-Free Bread-Like Products: Relationships Between Dough Rheology and Quality Characteristics. Food Bioprocess Technol. (2013),6:2331-2341.

[48] Bollinger, H.( 1992) Influence of apple pectin extract on the quality and freshness of baked goods. Food Marketing and Technology, 6: 6, 8, 10.

[49] Lafontan, M.; Langin, D.( 2009) Lipolysis and lipid mobilization in human adipose tissue. Prog. Lipid Res., 48, (5): 275-297.

[50] Cerd'a, B. ; Ceron, J.J. ; Tomas-Barberan, F.A. and Espin, J.C (2003) Repeated oral administration of high doses of pomegranate ellagitannin punicalagin to rats for 37 days is not toxic. J. Agric. Food Chem., 51, 3493

[51] Reed, J.D.( 1995) Nutritional toxicology of tannins and related polyphenols in forage legumes. J. Anim. Sci., 73, $1516-1528$

[52] Chalfoun-Mounayar, A. ; Nemr, R. ; Yared, P. ; Khairallah, S. and Chahine, R. (2012) Antioxidant and Weight Loss Effects of Pomegranate Molasses. Journal of applied pharmaceutical science, 02(06): 45-50. 
[53] Hossin, F.L.(2009) Effect of pomegranate (punica granatum) peels and its extract on obese hypercholesterolemic rats. Pakistan. Journal of Nutrition 8(8):1251-1257.

[54] Drent, M.L. and Van der Veen, E.A. (1995) First clinical studies with orlistat: a short review. Obes Res., 3 (Suppl 4): $623 \mathrm{~s}-625 \mathrm{~s}$

[55] Shanmugasundaram, K. R. ; Visvanathan, A. ; Dhandapani, K. ; Srinivasan, N. ; $\quad$ Rasappan, P. ; Gilbert, R., ; Alladi, S. ; Kancharla,S. and Vasanthi, N. (1986) Effect of high- fat diet on cholesterol distribution in plasma lipoproteins, cholesterol esterifying activity in leucocytes, and erythrocyte membrane components studied: importance of body weight. American Journal of Clinical Nutrition, vol. 44(6):805-815

[56] Aviram, M. ; Dornfeld, L. ; Kaplan, M. ; Coleman, R. ;Gaitini,
D. ; Nitecki, S. ;Hofman, A. ;Rosenblat, M. ;Volkova, N. ; Presser, D. ; Attias, J. ; Hayek, T. and Fuhrman, B. (2002) Pomegranate juice flavonoids inhibit low-density lipoprotein oxidation and cardiovascular diseases: studies in atherosclerotic mice and in humans, Drugs under Experimental and Clinical Research, vol. 28(2-3):49-62.

[57] Demori, I.; Voci, A.; Fugassa, E.; Burlando, B. (2006) Combined effects of high-fat diet and ethanol induce oxidative stress in rat liver. Alcohol, 40, 185-191.

[58] Fardet, A.; Llorach, R.; Martin, J. F.; Besson, C.; Lyan, B.; Pujos Guillot, E.; Scalbert.(2008) A liquid chromatography-quadrupole time-of-flight (LC-QTOF) based metabolomic approach reveals new metabolic effects of catechin in rats fed high-fat diets. J. Proteome Res., 7, (6): 2388-2398. 